Sunem Beaton-Garcia

\title{
Literary Feast
}

\section{A successful tool for library outreach}

$\mathbf{T}^{\mathrm{s}}$

he evening of November 1, 2011, was a

busy night for the University/College Library. Authors of books, articles and research studies, artists, playwrights, music composers, illustrators, photographers, and animators came together to meet with a group of more than 300 students to discuss their work and the publication process. The hum of conversation blended in with a jazz performance by a talented group of student musicians. Participants and attendees were tempted to partake in the sumptuous desserts and hors d'oeuvres. Why is this event taking place in the library? How did it come to be? And how did the library gather so many talented people? Let us tell you the story of how we managed to bring the library and faculty together for this remarkable event that has surpassed our wildest hopes.

It's no secret that library outreach to faculty is a challenge most academic libraries face. The University/College Library, a joint- use library for Broward College and Florida Atlantic University, is no different. Promoting library resources to two very different schools with different cultures that share the same campus has not been easy. The librarians at this very busy library have had various degrees of success with strategies to engage faculty but are always looking for new and innovative ways to reach more.

\section{Why a "feast"?}

To this end, we decided to do something completely different. We would have a party, a big party, to attract faculty that we would seldom see at the library. This was not to be a mixer or a luncheon, but an evening event with a cocktail party meet-and-greet vibe. The participants would be faculty members who have published work recently. The attendees would primarily be students. This would celebrate and showcase our faculty's work and draw them closer to the library. The concept was simple, the execution, as the reader will appreciate after reading this article, was anything but.

As with any project, we had to come up with objectives. What were we trying to accomplish?

1. Having work published or exhibiting work is no easy feat. This proud accomplishment is worth showcasing. Who would say no to that?

2. We wanted to provide an awareness of the talented and published authors who teach at both schools. In fact, many of our students graduate from one and enroll in the other. This would be a great opportunity for them to meet future professors.

3. We wanted to provide an opportunity for students to interact with professors as scholars outside of the classroom. Many only see their professors in one dimension; this would open their eyes to their expertise and contributions to their respective fields.

4. We wanted to establish a level of comfort with our library as a center of learning, and exchange of ideas. The library, for some, is a computer lab or a study space. But few, we found, see it as a place to express their thoughts and opinions.

5. This would be a great place to inform students who may be interested in the publishing process and even spark an interest in student research.

6. And lastly it would certainly encourage literacy, in all its forms. With these core values

Sunem Beaton-Garcia is reference and instruction librarian at University/College Library, e-mail: sbeaton@ broward.edu

๑) 2011 Sunem Beaton-Garcia 
in place we were ready to plan this ambitious event.

First we structured the event in a way that would appeal to the student. The format would allow students to make the choice of who they wanted to approach based on their interest. Unlike traditional literary events, we chose to not incorporate formal speeches or talks followed by a group discussion, but opted for a more relaxed open environment that would hopefully lead to interesting conversations based on the showcased work. We felt that this format would appeal more to demographics of our student body. Next, we discussed what we would name the event. We agreed to name it the Literary Feast because we hoped it would spark curiosity in our students and convey the idea of a banquet of information.

While we envisioned our

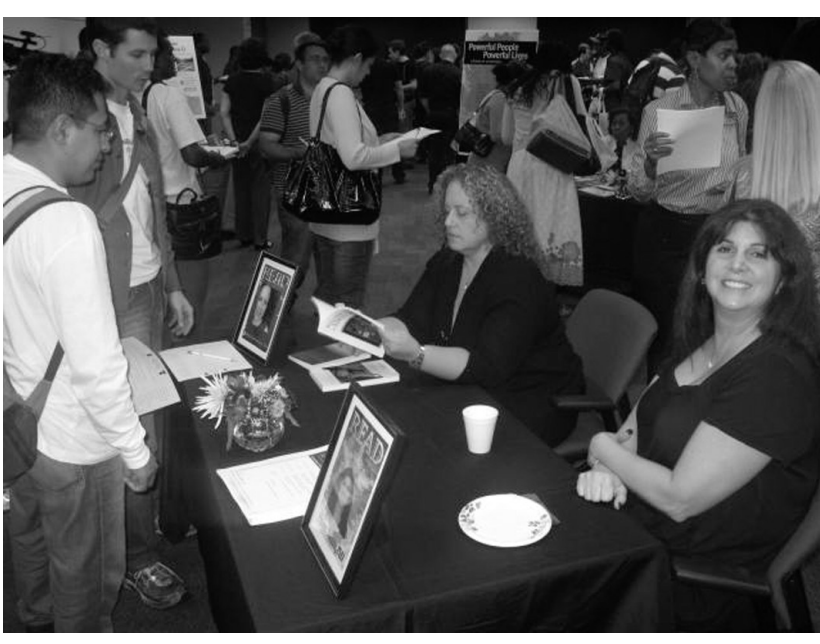

Rebecca MacKay of Florida Atlantic University and Helena Yeaman of Broward College interact with students at the Literary Feast.
To that end, we approached the student life department. We found that the department sponsors faculty-driven initiatives for student events. The Faculty Education Program (FEP) provides faculty members with a funding "to produce, promote, and facilitate learning opportunities outside the classroom."1 We applied for this program and received part of the funds requested. This would go towards refreshments and items such as table linens and flowers. Next, we approached the bookstore which generously provided a digital camera and other small give- event to include primarily authors of books and periodicals, we soon realized that our faculty has published their work in a number of ways, and we should not exclude them based on their medium of creative works. It turns out that the paintings, sculptures, and other fine arts enjoyed a great popularity among all of the showcased work. This, of course, was all very risky. Who would participate? Would the students come? How would we pay for this event?

\section{How we did it}

The first step was obtaining buy-in from library colleagues. Once the idea had been discussed, both on a one-and-one basis and at a department level, a core group agreed to organize the event. They in turn took on the responsibility to garner support, namely monetary, as the library did not have funds to pay for this initiative. also created eye-catching screensavers on the library computers as advertisements. The date for the first event was September 9, 2009. This was not a coincidence; we wanted an easy date to remember: 09-09-09. One of our screensavers was simply the date in white across a black background. The reader can only imagine how many students asked what that date represented. It was a very simple yet very effective promotional tool. As a result of our marketing efforts, we secured 18 interested faculty members as participants for our first event.

These participants came from a variety of areas and expertise within both institutions. We had six English professors, among them were mystery writers Neil S. Plakcy author of the Mabu Series, and Christine Kling author of Wreckers' Key. Our feast also included also nonfiction authors who created science textbooks 
and lab manuals and published research studies in the areas of nursing and history. Our college has very strong music and theater programs, and to represent them was professor and jazz musician Jason Hainsworth. One of the evening highlights were his students' performance songs from his last album Kaleidoscope.

In addition to these areas, our second feast drew increased participation from the fine arts and mathematics disciplines. Angie Shrick-Mathews showcased her new textbook Math in Our World. In the area of fine arts, we displayed several paintings created by Kyra Belan, whose award-winning work has been exhibited at many galleries across the country. Another popular participant among the students was pop-up books illustrator Karen Esteves. Her works include The Unicorn (pop-up carousel) and Share at Christmas (star origami). The students were fascinated by the tools and dexterity needed to create these intricate books. We encouraged participants to bring visual aids and copies of their work. This provided visual interest and stimulation and captured the curiosity of our students.

In order to ensure participation from our students instead of relying on walk-ins, we personally invited faculty who taught during that evening to bring in their classes. This turned out to be a good strategy. For the first feast one class attended for about half an hour. This attracted the attention of other students, and soon our event was a very busy place.

We also looked for ways to involve other students. As mentioned, we invited a student jazz band to perform, and they were the hit of the evening. At our last feast we asked them back and added student ambassadors as greeters. We also invited student clubs and student government organizations. This contributed greatly to the attendees of the second event. Part of our preparation was to create programs with a small biography of the participants. We also printed media releases and coordinated filming of the event. In addition, we made use of the in-house TV studios and taped interviews with the participants prior to the event. We later added all of the footage to a Libguide. ${ }^{2}$

What about the students once they arrived?
Could we rely on them to approach the participants? The solution came from one of our talented committee members, she created a simple icebreaker. This consisted of the student matching the name of the participating faculty with their publication title or work. Students may have been hesitant to approach the participants, so we thought this activity would help them approach the authors, and it later served as an entry for a chance at a giveaway.

The results of our first event were truly remarkable-more than 150 students attended. The faculty and administrators from both institutions appreciated our efforts on their behalf and invited us to present our program at the annual college-wide meetings.

Our second event attracted a crowd of more than 250, which included a local television crew and much larger prizes, such as a three-credit scholarship (courtesy of the Broward College Foundation), the college's bookstore donated an e-book reader, and the university's athletics department donated a dinner package bundled with tickets to athletics' game.

\section{What we learned}

- Beflexible. We envisioned this event to be campus-centered, yet we received interest from all campuses and satellite locations. At our last feast we had participation from all campuses for both schools. Be prepared to succeed.

- All hands on deck. This is truly a group effort. Managing large crowds, overseeing refreshments, greeting students, and putting out fires require lots of energy and warm bodies. So use other departments, student volunteers, and as many items as your disposal to help (i.e., golf carts).

- Promote. Promote. Promote. Attend campus meetings, faculty forums, and other such gatherings to get your message across.

- Relationships are everything. Locate allies on campus for mutually beneficial purposes. The bookstore enjoyed a greater patronage from our students and created an author's corner for faculty-authored works. Do not forget to include campus safety and the cleaning crew.

At our first event, we had a higher ratio of participants and attendees from one school. 
We realized that we would need folks on our committee from both institutions for a truly balanced event. That change resulted in a much larger representation from both schools. So, if possible, form a formal committee. This promotes better organization and accountability as well as documentation for the following year. This was the key to a much more successful event the second year.

We received very positive feedback from our first event from our participants and attendees via e-mail and personal communications. The second year, feedback was gathered proactively by way of a simple five-question anonymous survey. Here are some of the comments we received.

"It was nice to see the surprised expression on some of my students' faces to discover that I am a writer."- submitted via survey

"The Literary Feast has led to many follow-up conversations on Florida history with my students. One student in particular, who is also a native of Florida, continues to stop by my office and share stories about his ancestors in South Florida."- - submitted via survey

"The atmosphere was very comfortable; I have gotten to know my professors on a whole different level, I will be back next year." - student feedback 2009

In the end, these efforts have really paid off for us. We have reached faculty we would normally have not been able to reach, we have strengthen existing bonds, and, more importantly, the library is seen as a place to share ideas and as a place of learning on campus. Yes, the feast continues to be a tool for faculty outreach, but we have also found it has been a way to benefit our students.

\section{Notes}

1. Broward College (n.d.). Student life. Retrieved from www.broward.edu /studentlife/.

2. Literary Feast. 2009 [Web]. Available at http://libguides.ucl.broward.edu/content. php?pid=75659\&sid=1013675. Literary Feast. 2010 [Web]. Available at www.youtube.com /watch?v=K6YV2fJpmAs. $\boldsymbol{n}$

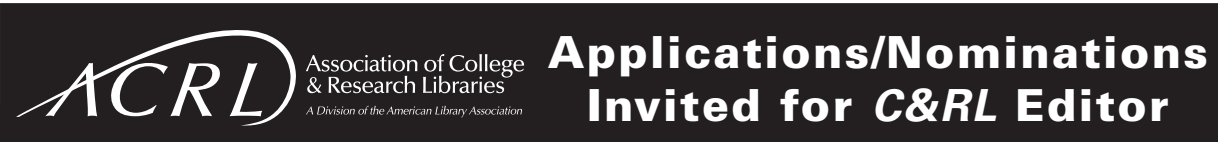

Applications and nominations are invited for the position of editor of College $\mathcal{E}$ Research Libraries (CERL), ACRL's bimonthly, scholarly research journal. The editor is appointed for a three-year term, which may be renewed for an additional three years. Applicants must be a member of ALA and ACRL. Qualifications include professional experience in academic libraries, a record of scholarly publication, editing experience, an ability to meet publication deadlines, an understanding of the scholarly communication process, and a broad knowledge of the issues confronting academic libraries.

Some funding for editorial assistance and travel to relevant conferences is available, and there is a small honorarium for the editor.
Appointment will be made by the ACRL Board of Directors at the 2012 Annual Conference upon the recommendation of the search committee and of the ACRL Publications Coordinating Committee. The incoming editor will serve for at least one year as editor-designate, working with the current editor, before assuming full responsibility for CERL in July 2013.

Nominations or resumes and letters of application, including the names of three references, should be sent to:
CERL Search Committee
c/o Dawn Mueller
ACRL, 50 East Huron Street
Chicago, IL 60611
e-mail: dmueller@ala.org 